\title{
Randomized controlled trial of comprehensive nursing intervention on readmission, mortality and quality of life among Egyptian heart failure patients: A 12 month follow up study
}

\author{
Amal Mohamed EI Badawy, Khadega Ahmed El Hefnawy \\ Menofia University, Egypt
}

Correspondence: Amal Mohamed El-Badawy. Address: Segine El-Kome, Kotour, Al Gharbia, Egypt. Email: amalbadawy@yahoo.com.

Received: July 4, 2012

Accepted: October 21, $2012 \quad$ Online Published: December 7, 2012

DOI : $10.5430 /$ jnep.v3n5p14

URL: http://dx.doi.org/10.5430/jnep.v3n5p14

\section{Abstract}

Background: Despite major advances in the treatment options for heart failure (HF) patients, morbidity and mortality remain high. Frequent re-admissions are distressful for patients and are associated with large costs for society. Improved self-care behaviour is a goal in educational programmes for patients with HF. The primary outcome measure of this study was to determine the effect of pre-discharge educational intervention and post- discharge intervention carried out by nursing staff on re-admission, mortality and quality of life.

Methods: A randomized controlled clinical trial in patients who were admitted to hospital with a diagnosis of HF. A total of 60 patients were randomly assigned (using a random number table) to either intervention group or a control group of 30 patients each. The intervention group participated in educational programme using face to face education before discharge, outpatient HF nursing intervention and monthly telephone call for over nine months to remind them about the main instruction in addition to the written instruction of HF management with emphasis on self-care behaviour. In each visit, the nurse evaluated the HF status and treatment, gave education about HF and social support to the intervention group. The control group received usual care and given a HF management written instruction.

Results: Patients in the intervention group was found to have a $66.67 \%$ decrease in the total number of readmission as compared to the control group ( 5 vs $25 ; p=.001$ ), fewer death ( 2 vs $6 ; p=.04$ ), and improved quality of life ( $t=27.06 ; P=$ .001). Furthermore, results showed significant improvement in HF knowledge level $(t=7.85 ; P=.001)$ and compliance of health behaviours ( $t=15.72 ; P=.001$ ), in the intervention group after 12 months of inclusion than those in the control group.

Conclusions: A comprehensive HF nursing intervention substantially reduced re-admission, death, increased compliance with self-management and improved HF QoL. The results of this study building on the work of others, suggest that all patients with HF should be offered pre-discharge education, post-discharge out-patient nursing support and monthly telephone follow up.

\section{Key words}

Heart Failure, Compliance of health behaviour, Quality of life, Morbidity, Mortality, Re-admission 


\section{I ntroduction}

Both prevalence and incidence of people living with heart failure (HF) increases drastically worldwide and the causes for this increase are due to the aging of the population over time and improvement of survival in patients suffering from coronary artery diseases (CAD) ${ }^{[1]}$. Egypt is experiencing a tidal rise of aging population, CAD, hypertension and diabetes ${ }^{[2,3]}$. This is inevitably reflected in the prevalence of cardiovascular diseases (CVD) in the community that was reported as the most common cause of mortality and health utilization in Egypt ${ }^{[4,5]}$. HF is a serious and costly CVD not only for patients and their families but also for society, because it associated with high mortality, marked disability and subsequent lack of productivity ${ }^{[6,7]}$. However, there is no published data about HF in Egypt, the National Heart Institute of Egypt in year 2003 found that Systolic HF patients required frequent re-admission and had a mortality rate of $17.6 \%$ vs $11.3 \%$ for diastolic HF patients, with a mean age 60 yrs and 63 yrs respectively ${ }^{[8]}$.

Heart failure is a complex syndrome in which the heart fails to pump adequately to meet the body's metabolic needs results in various pathological conditions and events which has associated with poor outcomes that result from a repeated de-compensated HF, furthermore this condition requiring multiple medication and frequent admission ${ }^{[9-13]}$. Both pharmacological and non-pharmacological therapy can complicate the treatment regimen from the patients' perspective, which make it more difficult to adherer non compliance with prescribed medical treatment and diet regimen contributes to worsening HF symptoms resulting in decreasing quality of life (QoL), increasing risk of mortality and morbidity, and increasing burden on home and health care system. Furthermore, HF patients often suffer from cognitive impairment, physical, psychological and social, functional disabilities, and multiple co- morbidities that often making normal daily life activity difficult, which further increases the complexity of patient management ${ }^{[7,14]}$.

Several studies have demonstrated that non compliance with medical treatment and diet regimen, inability to perform self-care behaviour, including monitoring systems of deterioration and failure to take action in order to prevent further deterioration, as well as the lacking of the professional intensive education and follow up in HF patients are associated with emergency visits and admission with worsening HF. The majority of this admissions is preventable ${ }^{[15-19]}$.

Previous researches ${ }^{[20-25]}$ found that majority of HF care is done at home by patient and family or caregiver. They identified that patients with HF having lack of knowledge and misconceptions about medication and on how to interpret and treat symptoms of deterioration, they did not understand the importance of daily weighing and one third patient believed they should drink a lot of fluids. Knowledge on self-care has also been shown poor. One of the most cost effective methods is to help people fight illness and disease by avoiding what is avoidable and prevent what is preventable. It is important these patients should believe that it is possible to obtain control over the disease ${ }^{[14]}$. Education and regular follow up that emphasizes self-management intervention are critical components of HF management programs ${ }^{[25]}$.

Within the increasingly complex HF management program, there is a significant role for the nurse to provide guidance, education, supportive follow up to those patients and their families ${ }^{[1]}$. The aim of this study was to determine the effect of pre-discharge educational program; post- discharge outpatient intervention and ongoing monitoring follow up carried out by nursing staff on re-admission, mortality and quality of life.

\section{Subjects and methods}

\subsection{Study design}

A randomized controlled clinical trial was conducted in Medical department at Menofia University Hospital which serves a wide socioeconomic range of patients in Shebine El-Kome city, Egypt. 


\subsection{Participations}

All patients in this convenience sample were recruited as a part of randomized control trial during their hospitalization and followed up after discharge in outpatient clinics monitored monthly via telephone calls. Sixty HF patients have completed this study. The inclusion criteria includes all those who had chronic HF, New York Heart Association (NYHA) class I to III symptoms, over 18 years of age to 80 years, residing within the surrounding area in Shebine -El-Kome, mentally alert, cared for themselves, able to read and write, had a telephone, and willing to participate. Patients were excluded if they had dementia documented by their attending physician, planned surgical correction for HF within 12 months as confirmed by patient medical record and history; cor-pulmonale, chronic renal failure on dialysis; psychiatric illness that made it impossible to respond to education; visual or auditory impairment; sever alcohol or drug abuse; terminal illness with life expectancy less than 6 months; or declined participation. Institutional Review Board approved the protocol and then consent was obtained from the patient who met the inclusion criteria. The participants' right was protected by explaining the study information form, significance of the study and their role for voluntary participation in this study, with the emphasis of no penalty or negative if they withdraw or quit at any time during the study. Flow chart in figure 1.

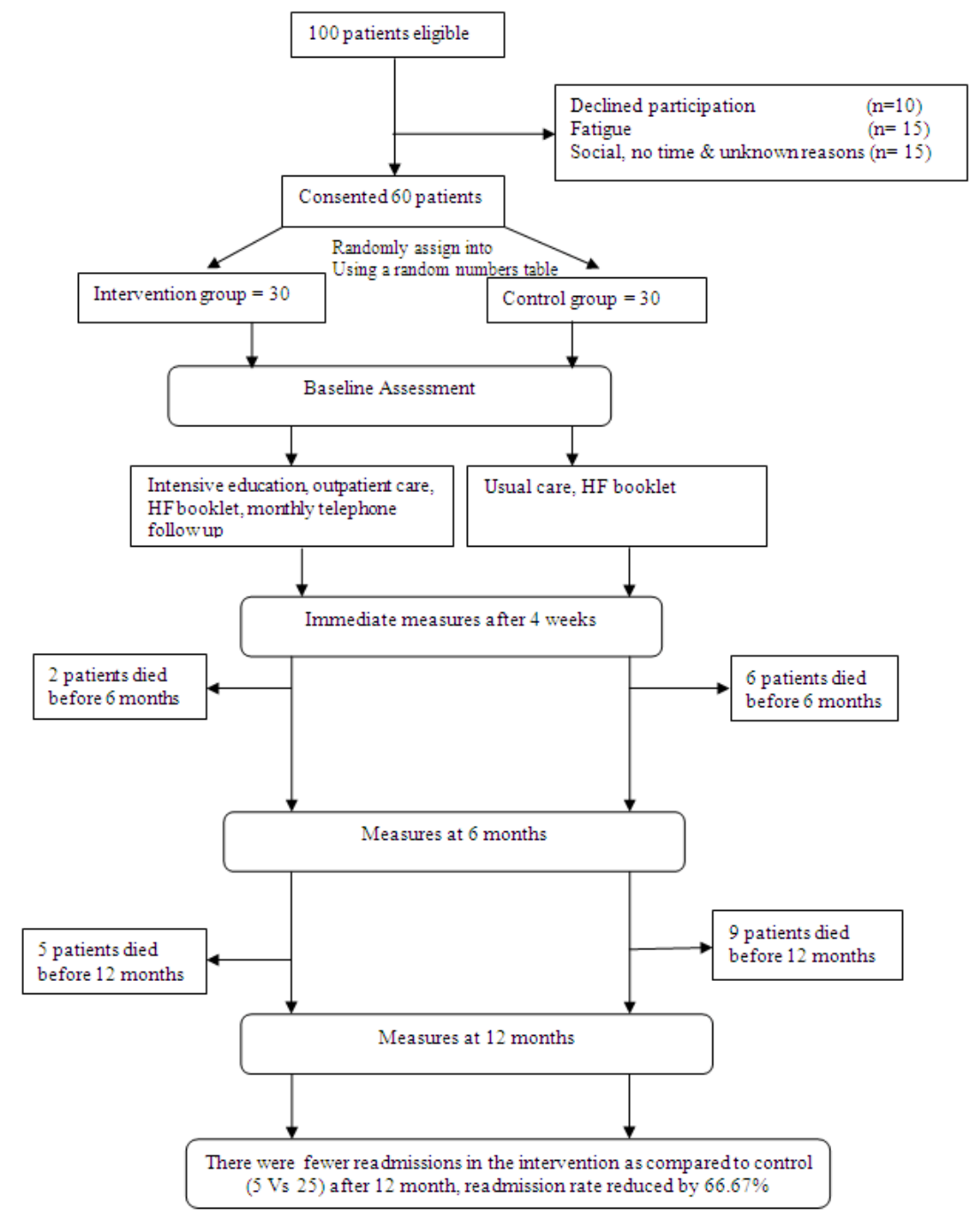

Figure 1. Flow Chart of the Study 
The clinical and sociodemographic variables (baseline) were measured before randomization for the study. Patients were assigned to the groups of 30 patients each (intervention and control) before hospital discharge using random number table. The intervention group participated in intervention program plus usual care and a control group received usual care.

\subsection{Hypothesis}

The researchers hypothesized that a pre-discharge educational intervention and post-discharge nursing support intervention, intended to increase compliance and empower patients to manage their disease, would significantly reduce the rate of readmission, death and demonstrate less health related quality of life impairment for patients with HF.

\subsection{Procedure}

Before data collection, the researchers developed HF booklets for this study and conducted training program for two nurses to assist in implementing the intervention program and data collection. They received four sessions about HF pharmacological and non-pharmacological management, patient interview, particularly on how to perform a monthly telephone interviews, each session lasting two hours. The use of the instrument was discussed extensively. At the time of enrolment, the patient was interviewed in his/her own bed to collect baseline data. the data gathering took place from December 2008 up to the end of March 2010.

\subsubsection{I ntervention group}

The intervention group received intensive educational session during their hospitalization for HF problem and then followed up by trained nurse during their scheduled visit at out-patient clinic. During patient clinic visit, the nurse did the history taking and physical examination, then recorded the vital signs and body weight. The nurse also completed health education that was initiated in the hospital before patient discharge. In Addition, the patient could communicate with the nurse any time the need arises.

The first visit was scheduled 1-4 weeks after discharge. The researchers evaluated the patient condition, if their condition is optimized, the researchers reviewed and updated their HF management knowledge, provided medical advice and social support. The physician met with the patient for his/her check up and the intervention plan was revised by nurses based on any changes in the patients prescription. Each visit continue for 1 hour and 30 minutes

Patient education can be defined as the process of improving knowledge and skills in order to influence the attitudes and behaviour required to maintain or improve health ${ }^{[19]}$. The educational intervention was based on guidelines and aimed to improve the patient's understanding of HF knowledge and improve self-management and lifestyle behaviours. As a part of the educational sessions, the patients were taught HF signs and symptoms and pharmacological and non-pharmacological management strategies that includes drugs, restrict fluid, fluid restriction along with sodium and alcohol intake, sodium and alcohol intake, perform daily weight assessment, detect the early signs of sodium and water retention "such as breathlessness, edema or weight gain up to $1.5-2 \mathrm{~kg} /$ week", and prevent malnutrition.

The educational program took nearly 40 to 60 minutes, divided into 2-3 sessions depending on the patient's tolerance. The education was individualized including written, verbal and interactive educational material that focused on the individual patient's learning needs and skills. The patients were given the educational booklet including management scenarios. The nurse and patient reviewed the booklet together. For example, the nurse first educated the patient about HF pharmacological and non-pharmacological management strategies, then engaged the patient in the discussion to solve the given self-management scenarios and encouraged him/her to use brain-storming to help the patient incorporate selfmanagement into their lives.

The researchers then made scheduled telephone follow up carried out monthly for 9 months period (starting the third month of intervention). Each call lasting 5-15 minutes and were designed to reinforce the educational session and provide motivation for the patients to comply with the management strategies. The nurse led telephone follow up emphasized body 
weight status, compliance of medication, fluid intake, and side effects of medication. Patients were also instructed to promptly call the nurse to report symptoms or any other problem during the weekdays. Patients experiencing worsening symptoms were scheduled for acute visits with their physician. Plan of care was changed accordingly

\subsubsection{Control group}

The control group did not receive nursing intervention program. Apart from this fact, both groups received the usual care during their hospitalization or at the time of discharge. Both groups received HF management booklet in advance as a data gathering tool. The control group received a monthly phone call as well, but the goal of these calls were to match the frequency of contact with the intervention group, there was no attempt made to match the duration of the telephone contact between groups.

\subsubsection{Evaluation and follow up}

Patient assessment and follow up were done with the single-blinded technique. The follow up was scheduled by their attending physician, who decided on the treatment and the date of discharge and was not aware of the group to which the patient had been assigned, in contrast to the research assistances and the person in charge of the statistical analysis.

All participants in both groups were assessed 4 times, first, baseline before intervention, second was immediately after the intervention ( 4 weeks after the start), third was six months and the fourth was twelve months after first intervention. Data were collected by means of personal interviews with patient and/or family and by reviewing the patient's medical records. All participants have a follow up card and a telephone contact to maintain communication during the study. .

\subsection{Instruments}

Based on review of relevant literature seven instruments were used in this study as the following:

\subsubsection{Sociodemographic and clinical data}

Sociodemographic variables were measured using designed survey, including age, gender, educational level, occupation, marital status and financial status Clinical information was obtained primarily from medical record such as, HF class, duration of HF, prescribed medication, previous HF hospitalization, hospital days and medical history.

Clinical characteristics New York Heart Association (NYHA) functional class and Charlson Comorbidity Index score were collected by the demographic and clinical questionnaires, medical records reviews, and the patient interviews. Comorbid illness was measured using the Charlson Comorbidity Index ${ }^{[26]}$. The Charlson Comorbidity Index was developed to assess the number and the seriousness of comorbid conditions that may impact the risk of mortality at enrollment. Patients' were queried about pre-existing disease. The final Charlson Index score was the sum of 19 predefined co-morbidities that were assigned weights of $1,2,3$, or 6 . Validity was supported in prior research in which comorbidity category predicated mortality and complications ${ }^{[6,22-28]}$.

The NYHA functional classification was developed to evaluate the effect of cardiac symptoms on daily activities of a cardiac patient, the limitations/symptoms are in regards to normal breathing and varying degree in shortness of breath, fatigue, palpitation and/or angina pain. The categories consists of 4 classes ranging from NYHA I (no symptoms that have an impact on ordinary daily activities) to IV (symptoms occur even at rest). The NYHA functional class was determined by in-depth interviews with patient using a standardized instrument by trained nurse research assistance ${ }^{[9,28]}$.

\subsubsection{Heart failure compliance questionnaire}

WHO defined the compliance as the extent to which a persons' behaviour (taking medication, following diet, and/or executing lifestyle changes) match with agreed recommendations from a heath care provider ${ }^{[30]}$. Heart Failure Compliance Scale was used to assess patient's compliance of health behaviours. This scale consisted of six health behaviours include, appointment keeping, medication, sodium restriction, fluid restriction, daily weighing, and exercise. 
Patients were asked to rate their own estimation of complying with each health behaviour on a 5-point Likert scale (0, never; 1 , seldom; 2, half of the time; 3 , mostly; and 4, always). Patients were asked to rate their compliance the last week (medication, diet, fluid restriction, and exercise), the last month (daily weighing), or the last 3 months (appointment keeping) before hospitalization. Patients were considered overall compliant' when they comply with four or more of the six specific recommendations. Internal consistency of the scale was tested by using Cronbach's alpha $(0.68){ }^{[30,31]}$.

\subsubsection{Patient HF knowledge questionnaire}

The patients' general knowledge of HF and its treatment were measured using a questionnaire. The questionnaire was a slight modification of a version used in the earlier studies. The questions in this scale were based on content of the CD-ROM program that based on issues of the European Heart Failure Self-Care Behaviour Scale ${ }^{[32-35]}$. The researchers developed 10-items scale. Patients were presented with 10 statement about heart failure as weight check is important to evaluate fluid retention, and were asked to response "yes", "No", or "I do not know". A correct answer was scored 1; an incorrect answer or an answer of "I do not know" was scored 0. Scores for each item were summed, giving range of total score from 0 to 10. Higher scores indicated greater knowledge about HF. The content validity of the scale was confirmed by an expert panel of experienced academic nurses in medical and surgical nursing field, physicians and cardiologists. Minor revisions of the wording were made based on the recommendations of these reviewers. Internal consistency of this questionnaire was tested by using Cronbach's alpha was .74.

\subsubsection{Health related quality of life (HRQOL)}

Quality of Life, defined as the degree to which aspects of patient's physical, social, functional, and emotional well-being are impacted by health ${ }^{[36]}$. Quality of Life was measured using the Minnesota Living with HF Questionnaire (MLHFQ) that developed by Rector, Kubo \& Cohn (1987). It consisted of 21 structured questionnaire that measures patient perceptions about the effects of a variety of physical, emotional and related impairment that relate to HF. MLHFQ items rated on 6-point of scale from 0 (no effect on quality of life) to 5 (greater effect), with a total maximum score of 105. High scores on the MLHFQ scales indicate worse quality of life. Respondents are asked to rate the degree to which each HF related impairment prevented them from living as they wanted during the previous month. The items combined to form an overall HRQOL score as well as physical health (8 items) and emotional health (5 items) scores. The physical subscale contained items associated with the fatigue and dyspnea of HF. The emotional subscale consisted of items such as being worried or feeling down. An additional 8 separate items, which do not assess a single construct or dimension of HRQOL, measure social and economical impairments patients related to their HF and are a part of the overall score ${ }^{[37,38]}$. The MLHFQ has been chosen in this study because it is a widely used disease-specific HRQOL questionnaire for HF with well documented validity, reliability and sensitivity in general population based samples, easily understood by ill and elderly individuals, and easy score. The reliability of MLHFQ has been reported with Cronbach's alpha ranging from .73 to $.93^{[39-42]}$.

\subsubsection{Rehospitalisation}

Rehospitalisation was determined by a combination of medical record review of hospital administrative records, and patient and family interview. Dates and reasons for all hospitalization were noted. Patients and families were interviewed to obtain self reports of admission that were used to validate data because of the possibility that a patient was admitted to a different hospital. In addition, patients were asked to keep a diary of all hospital admissions. The use of a variety of methods for tracking rehospitalizations ensured that all hospitalization were tracked and reasons for each were appropriately assigned ${ }^{[43]}$.

\subsubsection{Mortality}

Mortality was determined by a combination of medical record review, discussion with family, review of hospital records and review of death records to obtain date and cause of death. At enrolment, patients were asked for their contact information or a relative or close friend to be used if they are unable to be contacted. For patients whom the researcher was unable to reach by telephone, health care providers were contacted and hospital records were checked first to see whether 
the patient had died. If such evidence was not found, the friend or relative was contacted. If the patient or these contacts could not be located during follow-up, the death records were searched. These methods were used successfully to accurately categorize deaths in previous studies ${ }^{[43,44]}$.

\section{Data analysis}

Analysis was conducted according to the intention- to-treat approach, with readmission, mortality and quality of life as the primary outcome measure. Secondary end points included HF patient knowledge, compliance of health behaviour, causes of HF, duration of the disease, and length of hospital stay. Patients, who withdrew from the study after first and / or second visit, did not have outcome data for analysis. Data were summarized as numbers; percent; mean \& SD. Baseline differences between groups were assessed using chi - squire for categorical variables and Mann-Whitney test for continuous variables and Student's $t$ test for continuous, parametric variables. For HF knowledge, compliance of health behaviour and QoL, we used two-sample $t$-tests. Pearson correlations were calculated to identify the variables that significantly correlated with overall and individual scores of HF knowledge, compliance of health behaviour, numbers of re-admission, number of death and QoL score. All statistical analysis was performed using SPSS software package (Version 12.0). $P<.05$ was considered significant.

\section{Results}

\subsection{Demographic and clinical characteristics}

A total of 100 patients met the inclusion criteria, 10 patients declined to refuse participation, 15 patients declined to participate mainly due to fatigue, and 15 patients declined due to social, no times, \& unknown reason. A total of 60 patients consented to participate and were enrolled in the study. They were randomized assigned to either the intervention group $(n=30)$ or to control group $(n=30)$. Flow chart of the study trial profile is shown in figure 1 Demographic and clinical characteristics of both the intervention and control group are presented in table 1.

Table 1. Distribution of the studied sample according to their demographic and clinical characteristic

\begin{tabular}{|c|c|c|c|c|c|}
\hline \multirow{2}{*}{ Item } & \multicolumn{2}{|c|}{ Study group $(n=30)$} & \multicolumn{2}{|c|}{ Control group $(n=30)$} & \multirow{2}{*}{$P$ - value } \\
\hline & No & $\%$ & No & $\%$ & \\
\hline \multicolumn{6}{|l|}{ Sex } \\
\hline Men & 22 & 73.3 & 21 & 70.0 & $Z=-1.317$ \\
\hline Women & 8 & 26.7 & 9 & 30.0 & $P=.188$ \\
\hline \multicolumn{6}{|l|}{ Martial Status } \\
\hline Married & 23 & 76.7 & 20 & 66.67 & $Z=-1.009$ \\
\hline Widowed & 7 & 23.3 & 10 & 33.3 & $P=.313$ \\
\hline \multicolumn{6}{|l|}{ Education } \\
\hline Primary education & 5 & 16.7 & 3 & 10.0 & \multirow{3}{*}{$\begin{array}{l}\mathrm{Z}=-1.052 \\
P=.293\end{array}$} \\
\hline Secondary & 19 & 63.3 & 18 & 60.0 & \\
\hline University & 6 & 20.0 & 9 & 30.0 & \\
\hline \multicolumn{6}{|l|}{ Employment } \\
\hline Employed & 25 & 83.3 & 24 & 80.0 & \multirow{2}{*}{$\begin{array}{l}Z=-.331 \\
P=.741\end{array}$} \\
\hline Unemployed & 5 & 16.7 & 6 & 20.0 & \\
\hline \multicolumn{6}{|l|}{ Alcohol intake } \\
\hline Non drinker & 24 & 80.0 & 23 & 76.7 & \multirow{3}{*}{$\begin{array}{l}Z=-.350 \\
P=.727\end{array}$} \\
\hline$<3$ times/wk & 4 & 13.3 & 4 & 13.3 & \\
\hline$\geq$ 3times/wk & 2 & 6.7 & 3 & 10.0 & \\
\hline
\end{tabular}


Table 1. (continued)

\begin{tabular}{|c|c|c|c|c|c|c|}
\hline \multirow{2}{*}{ Item } & \multicolumn{2}{|c|}{ Study group, $n=30$} & \multicolumn{3}{|c|}{ Control group, $\mathrm{n}=30$} & \multirow{2}{*}{$P$ - value } \\
\hline & No & $\%$ & No & & $\%$ & \\
\hline \multicolumn{7}{|l|}{ Smoking } \\
\hline Yes & 11 & 36.7 & \multicolumn{2}{|l|}{16} & 53.3 & \multirow{2}{*}{$\begin{array}{l}\mathrm{Z}=-1.287 \\
P=.198\end{array}$} \\
\hline No & 19 & 63.3 & 14 & & 46.7 & \\
\hline \multicolumn{7}{|l|}{ Living situation } \\
\hline Living with relatives & 23 & 76.7 & \multicolumn{2}{|l|}{21} & 70.0 & \multirow{2}{*}{$\begin{array}{l}\mathrm{Z}=-.654 \\
P=.531\end{array}$} \\
\hline Living alone & 7 & 23.3 & 9 & & 30.0 & \\
\hline Duration of HF diagnosis, y & \multirow{2}{*}{\multicolumn{2}{|c|}{$2.37 \pm 1.43$}} & \multirow{2}{*}{\multicolumn{3}{|c|}{$2.90 \pm 1.99$}} & $t=-1.194$ \\
\hline Mean \pm SD & & & & & & $P=.238$ \\
\hline LOS* at inclusion / days & \multirow{2}{*}{\multicolumn{2}{|c|}{$8 \pm 2$}} & \multirow{2}{*}{\multicolumn{3}{|c|}{$8.27 \pm 2$}} & $t=.258$ \\
\hline Mean \pm SD & & & & & & $P=.798$ \\
\hline \multicolumn{7}{|l|}{ Previous hospitalization } \\
\hline With HF hospitalization & 12 & 40.0 & 13 & 43.3 & & \multirow{2}{*}{$\begin{array}{l}Z=-.260 \\
P=.795\end{array}$} \\
\hline Fist HF hospitalization & 18 & 60.0 & 17 & 56.7 & & \\
\hline \multicolumn{7}{|l|}{ Causes of HF } \\
\hline Ischemic heart disease & 13 & 43.3 & 9 & 30.0 & & \multirow{5}{*}{$\begin{array}{l}\mathrm{Z}=-1.700 \\
P=.073\end{array}$} \\
\hline Cardiomyopathy & 10 & 33.3 & 10 & 33.3 & & \\
\hline Valvular disease & 3 & 10.0 & 5 & 13.4 & & \\
\hline Congenital heart disease & 2 & 6.7 & 3 & 10.0 & & \\
\hline Hypertension & 2 & 6.7 & 3 & 10.0 & & \\
\hline \multicolumn{7}{|l|}{ Medication } \\
\hline ACE inhibitors & 10 & 33.3 & 10 & 33.3 & & \multirow{4}{*}{$\begin{array}{l}\mathrm{Z}=-.100 \\
P=.920\end{array}$} \\
\hline Diuretics & 9 & 30.0 & 8 & 26.7 & & \\
\hline Digoxin & 4 & 13.3 & 5 & 16.7 & & \\
\hline Beta blocker & 7 & 23.3 & 7 & 23.3 & & \\
\hline \multicolumn{7}{|l|}{ *Co-Morbidities } \\
\hline Ischemic heart disease & 13 & 43.3 & 9 & 30.0 & & \multirow{6}{*}{$\begin{array}{l}\mathrm{Z}=-.463 \\
P=.643\end{array}$} \\
\hline Peripheral vascular disease & 5 & 16.7 & 5 & 16.7 & & \\
\hline Chronic pulmonary disease & 6 & 20.0 & 5 & 16.7 & & \\
\hline Liver disease & 4 & 13.3 & 3 & 10.0 & & \\
\hline Diabetes & 6 & 20.0 & 7 & 23.3 & & \\
\hline Renal failure & 4 & 13.3 & 3 & 10.0 & & \\
\hline \multicolumn{7}{|l|}{ NYHA* } \\
\hline I & 8 & 26.6 & 6 & 20.0 & & \multirow{3}{*}{$\begin{array}{l}Z=.709 \\
P=.478\end{array}$} \\
\hline II & 11 & 36.7 & 10 & 33.3 & & \\
\hline III & 11 & 36.7 & 14 & 46.7 & & \\
\hline Age : Mean \pm SD & \multicolumn{2}{|c|}{$63.70 \pm 8.9$} & \multicolumn{3}{|c|}{$64.30 \pm 7.15$} & $\mathrm{t}=-1.397 ; P=.168$ \\
\hline
\end{tabular}

Note. $\mathrm{BP}=$ blood pressure; LOS = Length of hospital stay, Co-Morbidities percent, patient may have more than one problem, NYHA= New York Heart Association Classification

The groups were matched at baseline for age, sex, marital status, education, employment, alcohol intake and living situation. About $36.7 \%$ of the intervention group and $53.3 \%$ of the control group were smokers. The clinical characteristic of the study groups were matched for baseline duration of HF diagnosis, of previous hospitalization, HF cause, medication, NYHA class, Co-morbidities and length of hospital stay.

\subsection{Hospitalization or mortality}

It is clear from table 2, a fewer patients with events (hospitalization, death) among intervention group compared to the control group. The number of cardiac hospitalization during first 6 months follow up was significantly lower among intervention group compared to control group $(P<.002)$. Twelve months after inclusion, the number of patients who died 
almost twice higher in the control $(p<.001)$ and the readmission rate reduced by $66.67 \%$ in intervention group compared to in control group ( 5 vs $25 ; \mathrm{Z}=-1.989 ; P=.04$ ).

Table 2. Hospitalization and death Number in both intervention and control group after 6 and 12 months

\begin{tabular}{llll}
\hline Clinical events & $\begin{array}{c}\text { Study group } \\
(\mathbf{n = 3 0 )}\end{array}$ & $\begin{array}{c}\text { Control group } \\
(\mathbf{n = 3 0 )}\end{array}$ & $\boldsymbol{P}$-value \\
\hline Number of deaths & & & $\mathrm{Z}=-2.316 ; P=.02$ \\
After 6 months & 2 & 6 & $\mathrm{Z}=-1.989 ; P=.04$ \\
After 12 months & 5 & 9 & $\mathrm{Z}=-3.079 ; P=.002$ \\
$\begin{array}{l}\text { No. of patient with readmission } \\
\text { After 6 months }\end{array}$ & 27 & 45 & $\mathrm{Z}=-4.619 ; P=.001$ \\
After 12 months & 5 & 25 & \\
\hline
\end{tabular}

\subsection{Compliance rates, level of HF knowledge and quality of life}

Heart failure related knowledge; compliance of health behaviour, and quality of life improved more in the intervention group than in the control groups illustrated in figures 2 to 4 .

Figure 2. Health behaviour compliance mean score (theoretical range from 0 to 24), at baseline and after 3, 6, 12 months. Higher scores indicate better health behaviour compliance. The intervention group had better health behaviour compliance in the three assessments than the control group as compared to baseline.

Figure 3. Total HF knowledge mean score (theoretical range from 0 to 10 ) at baseline and after 3, 6, 12 months. Higher mean score indicate good knowledge. The intervention group had better knowledge than control group compared to baseline. However the level of knowledge declined in the intervention group but still better than control group.

Figure 4. Overall QOL mean scores (theoretical range from 0 to 105), Higher mean score indicate poor quality of life. At the baseline, both groups were similar QoL level. and 12 months later, the intervention group had better QOL than control group
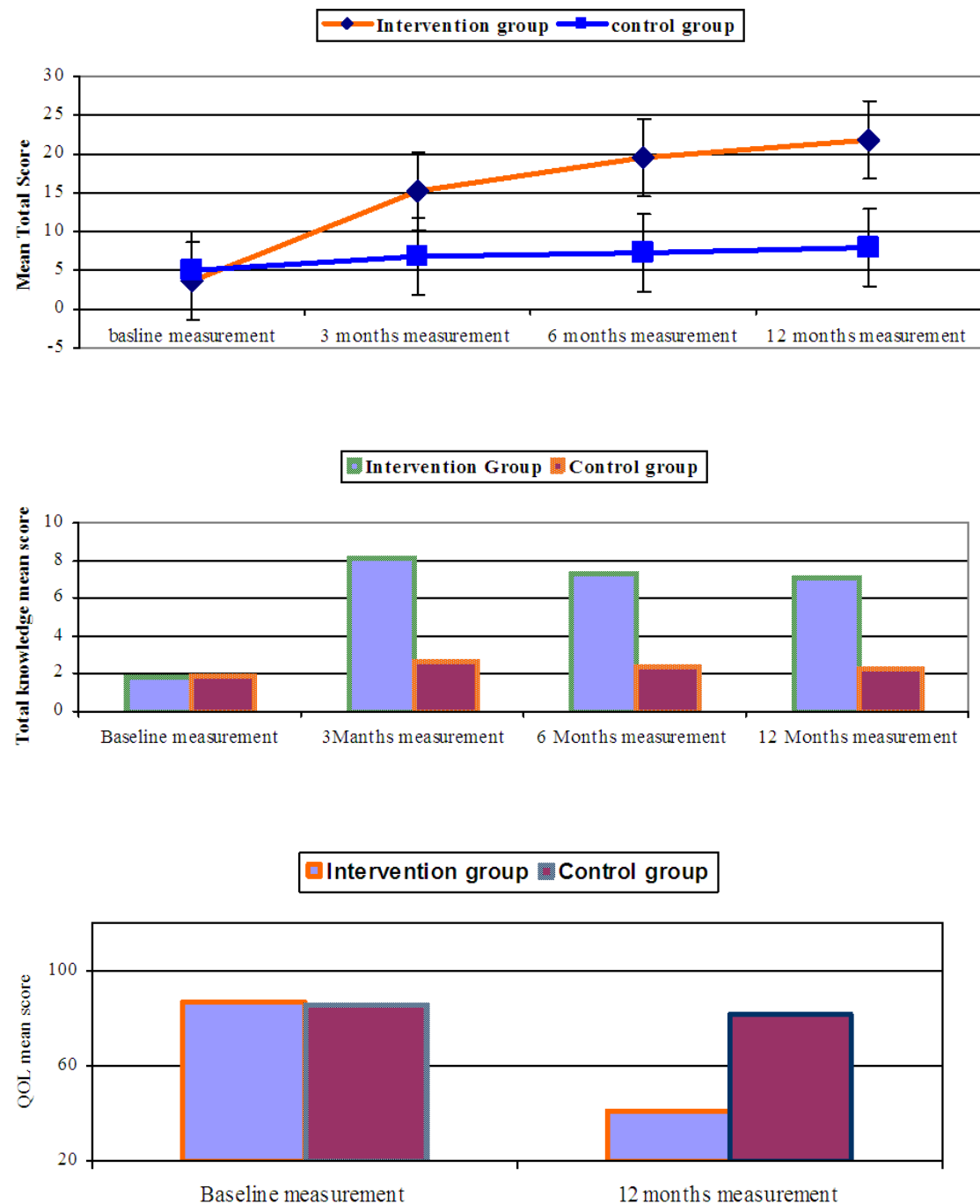


\subsection{Mean changes in HF patient's compliance of health behaviours, HF knowledge and quality of life in the both groups}

Table 3, shows mean score changes in HF patient's compliance of health behaviours, HF knowledge and HF quality of life over 12 months period among intervention and control group. Before the treatment, the compliance of health behaviour mean score was poor (3.53) among both the intervention and control group (4.94), and $t$-test indicated that the both groups did not significantly differ before the study intervention, $(t=1.48$; $P=.144)$. Twelve months after inclusion, the intervention group' compliance mean score was increased from 3.53 to 21.93 indicating that the intervention group had significantly improved compliance with health behaviour than those in the control group $(t=15.72, P<.01)$, with mean difference 13.96 between the both groups.

Table 3. Change in compliance of health behaviours, HF knowledge level and QoL over 12 month period among intervention and control group

\begin{tabular}{|c|c|c|c|c|}
\hline Variable & $\begin{array}{l}\text { Intervention group } \\
\text { Mean }( \pm \text { SD) }\end{array}$ & $\begin{array}{l}\text { Control group } \\
\text { Mean ( } \pm \text { SD) }\end{array}$ & Group difference & $P$-value \\
\hline \multicolumn{5}{|l|}{ HF compliance } \\
\hline Pre intervention & $3.53(3.98)$ & $4.94(3.32)$ & -1.40 & $t=-1.479 ; P=.14$ \\
\hline After 12 months & $21,93(2.25)$ & $7.97(3.62)$ & 13.96 & $t=15.719 ; P=.001$ \\
\hline \multicolumn{5}{|c|}{ Total knowledge score } \\
\hline Pre intervention & $1.83(1.87)$ & $1.90(2.05)$ & .10 & $t=-.131 ; P=.896$ \\
\hline After 12 month & $7.16(2.51)$ & $2.27(2.24)$ & 4.89 & $t=7.58 ; P=.001$ \\
\hline \multicolumn{5}{|l|}{ QoL } \\
\hline \multicolumn{5}{|l|}{ Emotional domain } \\
\hline Pre intervention & $21.23(3.61)$ & $20.83(3.49)$ & .400 & $t=.436 ; P=.664$ \\
\hline After 12 month & $.667(1.60)$ & $20.20(3.59)$ & -19.53 & $t=-27.24 ; P=.001$ \\
\hline \multicolumn{5}{|l|}{ Physical domain } \\
\hline Pre intervention & $33.03(5.24)$ & $32.23(5.37)$ & .800 & $t=.584 ; P=.561$ \\
\hline After 12 month & $2.60(2.74)$ & $30.667(5.23)$ & -28.07 & $t=-26.02 ; P=.001$ \\
\hline \multicolumn{5}{|l|}{ General domain } \\
\hline Pre intervention & $32.73(5.20)$ & $31.83(5.408)$ & .900 & $t=.657 ; P=.514$ \\
\hline After 12 month & $2.80(2.86)$ & $30.53(5.26)$ & -27.73 & $t=-25.362 ; P=.01$ \\
\hline \multicolumn{5}{|l|}{ Total QoL score } \\
\hline Pre intervention & $87.00(13.87)$ & $84.90(14.12)$ & 2.100 & $t=.581: P=.563$ \\
\hline After 12 month & $40.66(1.23)$ & 81.40 (13.69) & 40.74 & $t=-27.059 ; P=.001$ \\
\hline
\end{tabular}

The table also shows the comparison of HF knowledge mean score before treatment and 12 months post treatment that displayed a significant increase in the score of intervention group as compared with control group. Mean score was 1.83 before treatment to become 8.16 at second assessment and become 7.16 in. the last assessment among in the intervention group, however the level of knowledge declined in the intervention group but still better than control group. The mean difference between the two groups was 4.89 at the last follow up $(t=7.85 ; P<.01)$.

When we compared QoL mean scores before and after intervention between both groups, results indicated that after intervention, QoL mean score in the intervention group was less than that before intervention. In contrast QoL mean scorers before and after intervention of the control group were almost same (high) respectively. High scores on the MLHFQ scales indicate worse quality of life, as described in the instruments. When using "group difference score" on QoL between both groups, the mean difference was 40.74 . The $t$ test for the differences in the QoL change scores between two groups showed the intervention group had a significantly greater mean change score, as compared to the control group ( $t=27.06 ; P<.01$; see Table 3). These findings support the research hypothesis. 


\subsection{Correlation between HF knowledge and compliance of health behaviours, admission, mortality and QoL}

Table 4 shows that improvement in HF patient knowledge was positively correlated with the compliance of health behaviour $(r=.720 ; p=0.001)$ and reduce number of readmission $(r=.396 ; p=0.001)$ and negative correlation with quality of life $(r=-.687 ; p=0.001)$. It is clear from the table, quality of life negatively correlated with knowledge, re-admission and mortality. It may be that those patients who are relatively younger are used to making decisions about their health care, whereas older patients expect decisions to be made by the provider. Another interpretation is that older patients struggle relatively more with symptom recognition because of age-related change in interoception ${ }^{[4]}$.

Table 4. Correlation between HF knowledge, compliance of HF patient's of health behaviour, re-admission, mortality rate and QoL

\begin{tabular}{lllllll}
\hline & LS & Re-admission & Death rate & HF comp. & TKS & Quality of Life \\
\hline Living Situation & 1.00 & .028 & -.137 & -.109 & .058 & .113 \\
Re-admission & .028 & 1.00 & $.292^{*}$ & $.480^{* *}$ & $.396^{* *}$ & $-.559^{* *}$ \\
Death numbers & -.137 & $.292^{*}$ & 1.00 & $.263^{*}$ & .136 & $-.256^{*}$ \\
HF compliance. S & -.109 & $.480^{* *}$ & $.263^{*}$ & 1.00 & $.720^{* *}$ & $-.873^{* *}$ \\
Total know. Score & .058 & $.396^{* *}$ & .136 & $.720^{* *}$ & 1.00 & $-.687^{* *}$ \\
Quality of Life & .113 & $-.559^{* *}$ & $-.256^{*}$ & $-.873^{* *}$ & $-.687^{* *}$ & 1.00 \\
\hline
\end{tabular}

Note. LS= Living Situation , TKS = total knowledge score , HF camp S = HF patient' compliance health behaviour score

\section{Discussion}

Effective management of HF is one of the major challenges in health care today ${ }^{[15,29,46]}$. Non-compliance with the recommended treatment regimes is a widespread problem for HF patients, which can result in exacerbation of symptoms and hospital readmission, consequently become a costly exercise for both the patients and healthcare system. In recent studies, non-compliance with medication and diet was shown to be responsible for 21 to $55 \%$ of readmission and increase hospital stay ${ }^{[47,48]}$. Shearer et al. ${ }^{[49]}$ stated that increasing patient knowledge and the ability to recognize and manage symptoms are essential in the treatment of HF. Nurses play a substantive role in this endeavor, because they are the health care provider who most often provide support and teach self-care and symptom recognition and management to HF patient. They can offer discharge instruction and ongoing education that result in better patient self-care. Prevention of even a small number of readmissions to hospital could yield enormous saving in terms of hospital recourses and social cost and helping patients to live with optimal quality of life ${ }^{[50-54]}$.

In Egypt, nurse led heart failure clinics is not an established model for following up HF patients after discharge, in addition to a limited data in this field. There are many studies in Europe and USA evaluated nurse led follow up after hospitalization ${ }^{[6,46,55-58]}$ found prolonged time to readmission in patients followed up at the nurse-led outpatient clinic and a trend towards reduced number of admission and days in hospital and health costs. The different part in the current intervention, patient can easily access nurses by telephone, nurses facilitated compliance of health behaviour through education and remained with a correction of any misunderstand information and schedule for visit with doctor when they experiencing worsening signs and symptoms, especially edema, fatigue, dizziness or light-headedness, and dyspnea at rest or with activity. In addition to, we provide all participants with a written HF booklet about HF pharmacological and non-pharmacological management and explained the importance of HF education and self-care. In addition, the patients were followed up for 12 months period in attempt to make sure the patients takes maximum time to change behaviours and lifestyle that are enhanced from lifetime of habit.

Several randomized studies described the effect of interventions with a component of education and counseling on the improvement HF patients' compliance of health behaviours. In these successful programs, patients were educated and 
counseled by a nurses at the HF clinic ${ }^{[6,13,14,32,50,59]}$. The different parts in the current intervention in this, we engaged the patient in the discussion to solve the given self-management scenarios with a component of education session and encouraged him/ her to use brain-storming to help the patient incorporate self-management into their lives. Furthermore, although there have been smaller studies on the individual aspects of self-reported compliance (medication, appointment keeping, diet, fluid restriction, weighing and exercise) our study examines all dimensions of compliance after a face to face education that initiated before discharge, subsequent visits and monthly monitoring by telephone contact using a randomized controlled clinical trial, furthermore we examined the study outcomes for 4 times to assess the changes over time (before discharge to 12 months after discharge). The current findings of the study is consistent with the findings of van der Wal et al. ${ }^{[17]}$ and Evangelista et al. ${ }^{[31]}$ who found that the knowledge is important factor to improve HF patients' compliance. This is can be one important factor for the positive effect of the intervention, the patients were active in their self-care in order to prevent and at an early stage to detect any deteriorated in their health and lead them seeking for medical help ${ }^{[6]}$.

A growing number of intervention studies have aimed to reduce re-admission and mortality ${ }^{[6,16,54,56,60,61]}$. Our findings are consistent with these studies. The findings of this study provides further evidence that number of readmissions and mortality were significantly lower in the intervention group after 6 months and after 12 months compared to the control group. The readmission rate reduced by $66.67 \%$ after 12 months, but the major effect in the other studies up to $43 \%$ in Krumholz et al. ${ }^{[62]}$. We believe that higher decrease in events observed in this study is mainly due to the fact that, the intervention that implemented in this study, which initiated pre-discharge, provide the patient with HF booklet to help the participant recall what they had been taught by the nurse researcher and monthly telephone visit, which not only provide the opportunity for education, but also for detecting lack of compliance with pharmacological and non-pharmacological treatment and overcoming any barriers, thereby optimizing this factor. Moreover, since the interventions continue for three sessions after discharge, it was possible to detect early decompensation, which occurs in up to $40 \%$ of patients at 7-14 days after leaving the hospital ${ }^{[63,64]}$. This would make possible faster medical assessment, which is could prevent progressive clinical deterioration leading to subsequent hospitalization. Wongpiriyayothar et al. ${ }^{[63]}$ reported that providing intervention via the telephone improved physio-psychosocial well-being of patient with HF, in that study the intervention was telephone coaching at least twice weekly for three consecutive weeks, Wongpiriyayothar et al. study ${ }^{[63]}$ might support our result.

It is also likely that this type of follow up after hospitalization is cost effective. Data from Stewart et al. ${ }^{[64]}$ and Stromberg et al. ${ }^{[56]}$ suggest that when the reduction of hospital readmissions is above $40 \%$, the saving exceed the costs for nurse intervention. No attempt was made to calculate the specific financial benefit as a result of the current study intervention. This should take into account the involvement and time spent by each nurse during the education counseling, telephone contact. Therefore, the exact costs could be ascertained only on an arbitrary.

Quality of life is of enormous important to HF patients. HF is one of the chronic disease that most affects QoL ${ }^{[65]}$. Generally, a HF admission is accompanied by severe symptoms that can result in impaired QoL. Patients who survive this phase are expected to recover and stabilize at a higher level ${ }^{[66]}$. This is what observed in our study after comprehensive program. The current study findings show that most of the patients increased their QoL between their admission to the hospital and 12 months after discharge. This consistent with other studies ${ }^{[66-71]}$ which founded that a comprehensive HF management program lead to improved functional status, quality of life. It is clear from our study that compliance with health behaviour, re-admission, mortality and QoL were significantly positively related to improvement in the HF knowledge.

There are several potential limitations of this study. First, this study was on a small sample from one hospital. Replication on large sample and other hospitals are needed to support the generalization of the findings. Second, selection bias must be considered due to small convenience sample of patients from one hospital and not blinded for a research assistance nurses. Future studies should be conducted in patients who are newly diagnosed and in a larger sample, with a greater variety in 
health care provider included nurses background. Third, research assistances were not blind to group assignment during the assessment of self-reported outcomes. This effect could inflate patient responses to the subjective assessment compliance of health behaviour.

\section{Power}

The primary endpoints in this study were re-admission, death, and quality of life assessed at the 4 point longitudinal evaluations as explained above. The study was powered to detect significant differences in the intervention group compared to the control group. In this study, the readmission rate reduced by $66.67 \%$ after 12 months in the intervention group. There significant differences were detected between intervention and control group in readmission, death, and quality of life.

\section{Conclusions}

In conclusion, the comprehensive nursing intervention which includes, face to face pre-discharge education, postdischarge outpatient care and monthly telephone follow up had been shown to result in decrease hospital readmission, fewer deaths and improve in quality of life. Recently, studies ${ }^{[72-74]}$ stated that any intervention capable of decreasing even small fraction of the adverse outcome, most notably hospital admission and length of stay, could trigger significant cost saving in the management of HF.

Heart failure patients need education in order to adapt to their chronic condition and perform self-care behavior ${ }^{[19,45]}$. The results of this study also suggest that nurses need to initiate pre-discharge education to increase patient awareness of HF management and provide them with a written instruction to help them in recalling what they had been taught. The telephone is a feasible way to access patients at home.

We recommend the following for further study: need to assess and treat depressed HF patients, need a health economical analysis including all type of cost (medication, health care utilization, phone calls, booklet) to evaluate the total cost effectiveness of the current intervention, and we need a further research to study the same program with modification in the implementation for literacy patients, this is will be crucial for meeting the health care needs of the illiterate HF patients in Egypt.

\section{Acknowledgement}

I acknowledge Faculty of Nursing and Menofia University Hospital, for their support and give permission to conduct this study. My gratitude is extended to the patients with HF who participated in this study and to their attending physician. In addition, special thanks to Barbara E. Wolfe, PhD, APRN, FAAN, Associate Dean for Research and Professor William F. Connell School of Nursing, for her review and suggestion on the final version of this article.

\section{References}

[1] Joanne DB, Helene B, Jeroean H, Haske Vv. Effectiveness of self-management interventions on mortality, hospital readmission, chronic heart failure hospitalization rate and quality of life in patients with chronic heart failure: A systemic review. Patient Education and Counseling. 2010; 78: 297-315. PMid:20202778 http://dx.doi.org/10.1016/j.pec.2010.01.016

[2] Ibrahim MM, Rizk H, Appel LJ, et al. Hypertension prevalence, awareness, treatment, and control in Egypt. Results from the Egyptian National Hypertension Project (NHP). Hypertension. 1995; 26: 886-90. PMid:7490144 http://dx.doi.org/10.1161/01.HYP.26.6.886

[3] Herman WH, Ali MA, Aubert RE, et al. Diabetes mellitus in Egypt: risk factors and prevalence. Diabetic Med. 1995 ; $12: 1126-31$. PMid:8750225 http://dx.doi.org/10.1111/j.1464-5491.1995.tb00432.x

[4] Butala MN, Desal MM, Linnander EL, Wong RY, Mikhail DG, Ott LS, et al. Gender differences in presentation, management, and in-hospital outcomes for patients with AMI in a lower middle income country: evidence from Egypt. Plos One. 2011; 6 (10): e25904. www.plosone.org. PMid:22022463 http://dx.doi.org/10.1371/journal.pone.0025904 
[5] The Center Agency for Public Mobilization and Statistics (CAMPAS). The Annual Health Report of the year 1998. Cairo, Egypt: CAMPAS, 1998.

[6] Wu J-R, Moser DK, De Jong JM, Rayens KM, Chug IM, Riegel B, Lennie AT. Defining an evidence-based cut-point for medication adherence in heart failure. American Heart Journal. 2009; 157(2): 285-291. PMid:19185635 http://dx.doi.org/10.1016/j.ahj.2008.10.001

[7] Heo S, Moser DK, Lennine TA, Riegel B, Chung ML. Gender difference in and factors related to self-care behaviors: A cross-sectional, correlation study of patients with heart failure. International Journal of Nursing Studies. 2008; 45: 1807-1815. PMid:18674762 http://dx.doi.org/10.1016/j.ijnurstu.2008.05.008

[8] Ibrahim BS. The frequency of systolic versus diastolic heart failure in an Egyptian cohort. The European Journal of Heart Failure. 2003; 5: 41-45. http://dx.doi.org/10.1016/S1388-9842(02)00175-7

[9] Samir A, Nour W. Self-Management among Egyptian heart failure patients. International Journal of Nursing Practice. 2011; 17: 221-230. PMid:21605261 http://dx.doi.org/10.1111/j.1440-172X.2011.01929.x

[10] Andrei CL, Sinescu CJ, Oancea B, Iacob A. Methods used by students for development of socio-economics barriers in heart failure management. Procedia Social and Behavioral Sciences. 2010; 9: 1272-1276. Available online at www.sciencedirect.com.

[11] Haykowsky MJ, Liang Y, Pechter D, Jones LW, McAlister FA, Clark AM. A meta- analysis of the effect of exercise training on left ventricular remodeling in heart failure patients. Journal of the American College of Cardiology. 2007; 49 (24): $2329-36$. PMid:17572248 http://dx.doi.org/10.1016/j.jacc.2007.02.055

[12] Gwadry-Sridhar F, Guyatt G, O'Brien B, Arnold JM, Walter S, Vingilis E, Mackeigan L TEACH: Trial of education and compliance in heart dysfunction chronic disease and heart failure (HF) as an increasing problem. Contemporary Clinical Trials. 2008; 29: 905-918. PMid:18703166 http://dx.doi.org/10.1016/j.cct.2008.07.001

[13] DeWalt DA, Malone RM, Bryant ME, Kosnar MC, Corr KC, Rothman RL, et al. A heart failure self-management program for patients of all literacy levels: A randomized, controlled trial [ISRCTNI 1535170]. BMC Health Services Research. 2006 ; 6:30. Available at http://www.biomedcentral.com/1472-6963/6/30 PMid:16533388 http://dx.doi.org/10.1186/1472-6963-6-30

[14] Holst M, Willenheimer R, Martensson J, Lindholm M, Stromberg A. Telephone follow up of self carebehaviour after a single session education of patients with heart failure in primary health care. European Journal of Cardiovascular Nursing. 2007; 6: 153-159. PMid:16928469 http://dx.doi.org/10.1016/j.ejcnurse.2006.06.006

[15] van der Wal MH, Tiny J. Adherence in heart failure in the elderly: problem and possible solutions. International Journal of Cardiology. 2008; 125: 203-208. PMid:18031843 http://dx.doi.org/10.1016/j.ijcard.2007.10.011

[16] Heart Failure Society of America. HFSA. Comprehensive heart failure practice guideline. J Card Fail. 2006 ; 12 (1): $10-65$. PMid:16500578 http://dx.doi.org/10.1016/j.cardfail.2005.12.001

[17] Van der wal HL, Jaarsma T, Moser DK, Veeger JG, van Gilst WH, van Veldhuisen DJ. Compliance in heart failure patients: the importance of knowledge and beliefs. European Heart Journal. 2006; 27: 434-440. PMid:16230302 http://dx.doi.org/10.1093/eurheartj/ehi603

[18] Michalsen A, Konig G, Timme W. Preventable causative factors leading to hospital admission with decompensated heart failure. Heart. 1998; 80: 437-41. PMid:9930040

[19] Stromberg A. The crucial role of patient education in heart failure. The European Journal of Heart Failure. 2005; 7: 363-369. PMid:15718176 http://dx.doi.org/10.1016/j.ejheart.2005.01.002

[20] Phillips CO, Wright SM, Kern DE, Singa RM, Shepperd S, Rubin HR. Comprehensive discharge planning with post discharge support for older patients with congestive heart failure. A Meta analysis. JAMA. 2004; 291(11): 1358-67. PMid:15026403 http://dx.doi.org/10.1001/jama.291.11.1358

[21] Boyd JK, Murray AS, Kendall M, Worth A, Frederick BT, Clausen H. Living with advanced heart failure: a prospective, community based study of patients and their cares. Eur J Heart Failure. 2004; 6: 585-91. PMid:15302006

[22] Horowitz RC, Rein BS, Leventhal H. A story of maladies, misconceptions and mishap: effective management of heart failure. SocSci Med. 2004; 58: 631-43. http://dx.doi.org/10.1016/S0277-9536(03)00232-6

[23] Sneed N, Paul S. Readiness for behavioural changes in patients with heart failure. Am J Crit Care. 2003 ; 12 : $444-53$. PMid:14503428

[24] Ni H, Nauman D, Burgess D, Wise K, Crispell K, Hershberger R.E. Factors influencing knowledge of and adherence to self-care among patients with heart failure. Arch Intern Med. 1999; 159: 1613-9. PMid:10421285 http://dx.doi.org/10.1001/archinte.159.14.1613

[25] Rogers A, Addington-Hall J, McCoy A, Edmonds P, Abery A, Coats A. et al. A qualitative study of chronic heart failure patients' understanding of their symptoms and drug therapy. Eur J Heart Fail. 2002; 4:283-7. http://dx.doi.org/10.1016/S1388-9842(01)00213-6 
[26] Charlson ME, Pompei P, Ales KL, et al. Anew method of classifying prognostic comorbidity in longitudinal studies: development and validation. J Chronic Dis. 1987; 40:373-83. http://dx.doi.org/10.1016/0021-9681(87)90171-8

[27] Ramiarina RA, Ramiarina BL, Almeida RM, Pereira WC. Comorbidity adjustment index for the international classification of diseases, 10th revision. Rev SaudePublica. 2008; 42(4): 590-7. PMid:18709238 http://dx.doi.org/10.1590/S0034-89102008000400003

[28] Bennett JA, Riegel B, Bittner V, Nichols J. Validity and reliability of the NYHA classes for measuring research outcomes in patients with cardiac disease. Heart and Lung. 2002; 32(4): 262-270. http://dx.doi.org/10.1067/mhl.2002.124554

[29] Smeulders E, CM van Haastregt J, FM van Hoef E, ThM van Eijk J, IJM Kempen G. Evaluation of a self- management programme for congestive heart failure patients: design of a randomized controlled trial. BMC Health Services Research .2006; 6:91. PMid:16857049 http://dx.doi.org/10.1186/1472-6963-6-91

[30] Riegel B, Carlson B, Glaser D. Development and testing of a clinical tool measuring self-management of heart failure. Heart \& Lung. 2000; 29:4-12. http://dx.doi.org/10.1016/S0147-9563(00)90033-5

[31] Evangelista LS, Berg J, Dracup K. Relationship between psychosocial variables and compliance in patients with heart failure. Heart Lung. 2001; 30: 294-301. PMid:11449216 http://dx.doi.org/10.1067/mhl.2001.116011

[32] van der Wal MHL, Jaarsma T, Moser DK, van Veldhuisen DJ. Development and testing of the dutch heart failure knowledge scale. European Journal of Cardiovascular. 2005; 4: 273-277. PMid:16126459 http://dx.doi.org/10.1016/j.ejcnurse.2005.07.003

[33] Linne AB, Liedholm $\mathrm{H}$. Effects of an interactive CD-program on 6 months readmission rate in patients with heart failure-a randomized, controlled trial. BMC Cardiovascular Disorders. 2006; 6: 30. PMid:16796760 http://dx.doi.org/10.1186/1471-2261-6-30

[34] Stromberg A, Ahlen H, Fridlund B, Dahlstrom U. Interactive education on CD-ROM a new tool in the education of heart failure patient. Patient educCouns. 2002; 46: 75-81. http://dx.doi.org/10.1016/S0738-3991(01)00151-3

[35] Jaarsma T, Stromberg A, Martensson J, Dracup K. Development and testing of the European Heart Failure Self Care Behaviour Scale. Eur J Heart Filure. 2003; 5: 363-370. http://dx.doi.org/10.1016/S1388-9842(02)00253-2

[36] Loughlin CO, Murphy NF, Conlon C, O’Donovan A, Ledwidge M, McDonald K. Quality of life predicts outcome in a heart failure disease management program. International Journal of Cardiology. 2010; 139: 60-67. PMid:18851887 http://dx.doi.org/10.1016/j.ijcard.2008.09.003

[37] Rector TS, Cohn J.N. Assessment of patient outcomes with the Minnesata living with heart failure questionnaire: reliability and validity during a randomized, double-blind, placebo-controlled trial of pimobendan. Am Heart J. 1992; 124: 1017-25. http://dx.doi.org/10.1016/0002-8703(92)90986-6

[38] Rector TS, Kubo SH, Cohn JN. Validity of the Minnesata living with heart failure questionnaire as a measure of therapeutic response to enalapril or placebo. Am J Cardiol. 1993; 71: 1106-7. http://dx.doi.org/10.1016/0002-9149(93)90582-W

[39] Supino PG, Borer JS, Franciosa JA, Preibisz JJ, Hochreiter C, Isom OW, et al. Acceptability and psychometric properties of the Minnesota living with heart failure questionnaire among patients undergoing heart valve surgery: validation and comparison with SF-36. Journal of Cardiac Failure. 2009; 15 (3): 267-277. PMid:19327629 http://dx.doi.org/10.1016/j.cardfail.2008.10.003

[40] Meyer K, Laederach-Hofmann K. Effect of a comprehensive rehabilitation program on quality of life in patients with chronic heart failure. ProgCardiovascNurs. 2003; 18: 169-76. PMid:14605517 http://dx.doi.org/10.1111/j.0889-7204.2003.03013.x

[41] Middel B, Bouma J, Jongste MD, van Sonderen E, Niemeijer MG and van den Heuvel W. Psychometric properties of the Minnesota living with heart failure questionnaire (MLHF-Q). Clinical Rehabilitation. 2001; 15: 489-500. PMid:11594639 http://dx.doi.org/10.1191/026921501680425216

[42] Riegel B, Moser DK, Glaser D, Carlson B, Deaton C, Armola R, et al., The Minnesota Living with Heart Failure Questionnaire: sensitivity differences and responsiveness to intervention intensity in a clinical population. Nursing Research. 2002 ; 52 (4): 209-215. http://dx.doi.org/10.1097/00006199-200207000-00001

[43] Wu J-R, Moser DK, Chung ML, Lennie TA. Objectivity measured, but not self-report, medication adherence independently predicts event-free survival in patients with heart failure. Journal of Cardiac Failure. 2008; 14(3): 203-210. PMid:18381183 http://dx.doi.org/10.1016/j.cardfail.2007.11.005

[44] Moser DK, Stevenson WG, Woo MA, Stevenson LW. Timing of sudden death in patients with heart failure. J Am CollCardiol. 1994; 24: 963-7. http://dx.doi.org/10.1016/0735-1097(94)90856-7

[45] Riegel B, Driscoil A, Suwanno J, Moser DK, Lennie TA, Chung ML, et al. Heart failure self-care in developed and developing countries. Journal of Cardiac Failure. 2009; 15 (6): 508-516. PMid:19643362 http://dx.doi.org/10.1016/j.cardfail.2009.01.009

[46] Martensson J, Stromberg A, Dahlstrom U, Karlsson JE, Fridlund B. Patients with heart failure in primary health care effects of a nurse-led intervention on health related quality of life and depression. Eu J Heart. 2005; 7: 393-403. PMid:15718180 http://dx.doi.org/10.1016/j.ejheart.2004.01.016 
[47] Van der Wal MHL, Jaarsma T, Moser DK, van Gilst WH. Qualitative examination of complication of compliance in heart failure patients in the Netherlands. Heart and Lung. 2010; 39: 121-130. PMid:20207272 http://dx.doi.org/10.1016/j.hrtlng.2009.07.008

[48] Opasich C, Rapezzi C, Lucci D, Gorini M, Pozzar F, Zanelli E., et al. Precipitating factors and decision-making processes of short-term worsening heart failure despite “optimal” treatment (from the IN-CHF Registry). Am J Cardiol. 2001; 88: 382-7. http://dx.doi.org/10.1016/S0002-9149(01)01683-6

[49] Shearer NBC, Cisar N, Greenberg EA. A telephone-delivered empowerment intervention with patients diagnosed with heart failure. Heart \& Lung. 2007; 36: 159-169. PMid:17509423 http://dx.doi.org/10.1016/j.hrtlng.2006.08.006

[50] Albert NM. Improving medication adherence in chronic cardiovascular disease. Critical Care Nurse. 2008; 28(5):54-64. PMid:18827087

[51] Anderson C, Deepak BV, Amoateng-Adjepong Y, Zarich S, Benefits of comprehensive inpatient education and discharge planning combined with outpatient support in elderly patients with congestive heart failure. Congest Heart Failure. 2005; 11(6): 315-321. PMid:16330907 http://dx.doi.org/10.1111/j.1527-5299.2005.04458.x

[52] Petrilla AA, Benner JS, Battleman DS, Tierce JC. Hazard EH. Evidence-based interventions to improve patient compliance with antihypertensive and lipid lowering medications. Int J ClinPract. 2005; 59: 1411-1451. PMid:16351677 http://dx.doi.org/10.1111/j.1368-5031.2005.00704.x

[53] Lambrinou E, Kalogirou F, Lamnisos D, Sourtzi P. Effectiveness of heart failure management programmes with nurse-led discharge planning in reducing re-admission: A systemic review and meta-analysis. International Journal of Nursing Studies. 2012; 49: 610-624. PMid:22196054 http://dx.doi.org/10.1016/j.ijnurstu.2011.11.002

[54] Cline C, Israelsson B, Willenheimer R et al. Cost effective management programme for heart failure reduces hospitalization. Heart. 1998; 80: 442-6. PMid:9930041

[55] Ekman I, Andersson B, Ehnfors M et al. Feasibility of a nurse-monitored, outpatient-care progamme for elderly patients with moderate-to-severe, chronic heart failure. Eur Heart J. 1998; 19:1254-60. PMid:9740348 http://dx.doi.org/10.1053/euhj.1998.1095

[56] Stromberg A, Martensson J, Fridlund B, Levin L-A, Karlsson J-E, Dahlstrom U. Nurse-led heart failure clinics improve survival and self care behavior in patients with heart failure. Eur Heart Journal. 2003; 24: 1014-1023. http://dx.doi.org/10.1016/S0195-668X(03)00112-X

[57] Angelidou D. Caring for the heart failure patient: Contemporary nursing interventions. Hospital chronicles 2010, supplement: 1-8. Available from: www.hospitalchronicless.gr/index.php/h

[58] Andersson B, Kjork E, Brunlof G. Temporal improvement in heart failure survival related to the use of a nurse-directed clinic and recommended pharmacological treatment. International Journal of Cardiology. 2005; 104: 257-263. PMid:16186053 http://dx.doi.org/10.1016/j.ijcard.2004.10.028

[59] Nieuwenhuis MMW, Jaarsma T, van Veldhuisen DJ, Postmus D, van der wal MHL. Long-Term compliance with non-pharmacologic treatment of patients with heart failure. The American Journal of cardiology in press.

[60] Albert NM, Buchsbaum R, Li J. Randomized study of the effect of video education on heart failure healthcare utilization, symptoms, and self-care behaviors. Patient Education and Counseling. 2007; 69: 129-139. PMid:17913440 http://dx.doi.org/10.1016/j.pec.2007.08.007

[61] Ryan M, Aloe K, Mason-Johnson J. Improving self management and reducing hospital readmission in heart failure patients. Clinical Nurse Specialist. 2009; 23 (4): 216-221. http://dx.doi.org/10.1097/NUR.0b013e3181a8ca4e

[62] Krumholz HM, Amatruda J, Smith GL et al. Randomized trial of an education and support intervention to prevent readmission of patients with heart failure. J CollCardiol. 2002; 39: 83-9. http://dx.doi.org/10.1016/S0735-1097(01)01699-0

[63] Wongpiriyayothar A, Piamjariyakul U, Williams PD. Effects of patient teaching, educational materials, and coaching using telephone on dyspnea and physical functioning among persons with heart failure. Applied Nursing Research. 2011 ; 24 : e59-e66. PMid:20974096 http://dx.doi.org/10.1016/j.apnr.2010.02.007

[64] Stewart S, Blue L, Walker A et al. An economic analysis of specialist heart failure nurse management in the UK: Can we afford not to implement it? Eur Heart J. 2002; 23: 1369-78. PMid:12191748 http://dx.doi.org/10.1053/euhj.2001.3114

[65] Parajon T, Lupon J, Gonzalez B, Urrutia A, Altimir S, Coll R, et al. Use of the “Minnesota Living with Hear Failur” Quality of life questionnaire in Spain. 2003; 57 (2): 155-60.

[66] Barbarschi G, Sanderman R, Leegte JL, van Veldhuisen DJ, Jaarsma T. Educational level and the quality of life of heart failure patients: A longitudinal study. Journal of Cardiac Failure. 2011; 17 (1): 47-53. PMid:21187264 http://dx.doi.org/10.1016/j.cardfail.2010.08.005

[67] Coats AJ. Advance in the non- drug, non surgical, non device management of chronic heart failure. International Journal of cardiology. 2005; 100: 1-4. PMid:15820278 http://dx.doi.org/10.1016/j.ijcard.2005.01.005

[68] Vavouranakis I, Lambrogiannakis E, Markakis G, Dermitzakis A, Haroniti Z, Ninidaki C, Borbantonaki A, ndTsoutsoumanou K. Effect of home based intervention on hospital readmission and quality of life in middle-aged patients with severe congestive heart 
failure: a 12-month follow up study. Eur Journal Cardiovascular Nursing. 2003; 2: 105-111. http://dx.doi.org/10.1016/S1474-5151(03)00006-9

[69] Lewis EF, Lamas GA, Meara EO, Granger CB, Dunlap ME, Mckelvie RS, et al. Characterization of health-related quality of life in heart failure patients with preserved versus low ejection fraction in CHARM. The European Journal of Heart Failure. 2007; 9: 83-91. PMid:17188020 http://dx.doi.org/10.1016/j.ejheart.2006.10.012

[70] Jaarsma T, Nikolova-Simons M, van der Wal MHL. Nurses’ strategies to address self-care aspects related to medication adherence and symptom recognition in heart failure patients: An in-depth look. Heart \& Lung, in press.

[71] Sherwood A, O’Connor CM, Routledge FS, Hinderliter AL, Watkins LL, Babyak MA, et al. Coping effectively with heart failure (COPE-HF): Design and Rational of a telephone-based coping skills intervention. Journal of Cardiac Failure. $2011 ; 17$ (3): 201-207. PMid:21362527 http://dx.doi.org/10.1016/j.cardfail.2010.11.001

[72] Holst DP, Kaye D, Richardson M, Krum H, Prior D, Aggarwal A. Improved outcomes from a comprehensive management system for heart failure. The European Journal of Heart Failure. 2001; 3: 619-625. http://dx.doi.org/10.1016/S1388-9842(01)00164-7

[73] Morcillo C, Valderas JM, Aguado O, Delas J, Sort D, Pujadas R, Rosell F. Evaluation of a home based intervention in heart failure patients. Results of a randomized study. Rev EspCardiol. 2005; 58(6): 618-25. PMid:15970116 http://dx.doi.org/10.1157/13076413

[74] Ho Y-L, Hsu T-P, Chen C-P, Lee C-Y, Lin Y-H, Hsu R-B. Improved cost effectiveness for management of chronic heart failure by combined home based intervention with clinical nursing specialists Formos Med Assoc. 2007; 106 (4): 313-319. 